\title{
Introducción a la valoración de daños (con aplicación al arbitraje)
}

\author{
Oswaldo Santos Dávalos*
}

\begin{abstract}
SUMARIO: 1. Introducción. 2. Objetivo del régimen de daños. 3. Métodos de valoración. 3.1. Los métodos intrínsecos (y el flujo de fondos descontado). 3.2. Los métodos relativos. 3.3. Los métodos basados en el valor de los activos. 3.4. Otros aspectos relevantes en la valoración. 4. Consideraciones jurídicas. 4.1. Causa del daño. 4.2. Tipo del daño. 4.3. Cláusula penal. 4.4. Congruencia. 4.5. Mora. 4.6. Exposición al daño. 4.7. Mitigación del daño. 5. Resumen y conclusiones.
\end{abstract}

\section{Introducción}

Prevalecer con una demanda arbitral es una tarea compleja ${ }^{1}$. Primero se debe convencer al tribunal de que es competente para dirimir la controver$\operatorname{sia}^{2}$. Luego, a más de cumplir con una serie de presupuestos procesales ${ }^{3}$, debe demostrarse la existencia del daño y que el demandado es responsable. Pero todo eso no basta: probar la existencia del daño no garantiza que el actor vaya a recibir el resarcimiento que espera, ya que tiene también la carga de demostrar la cuantía de los perjuicios que ha sufrido.

*Socio de Santos Burbano de Lara | Abogados; profesor de la Universidad San Francisco de Quito y de la Universidad Andina Simón Bolívar, cofundador del Instituto Iberoamericano de Derecho y Finanzas; M. Sc. en Derecho y Finanzas por la Universidad de Oxford, abogado summa cum laude por la Universidad San Francisco de Quito y economista por la Universidad Técnica Particular de Loja.

1. Por ejemplo, únicamente el $46 \%$ de los laudos proferidos bajo las reglas CIADI admitió las pretensiones del reclamante en todo o en parte. El 28\% de los laudos rechazó la solicitud de arbitraje en su totalidad y el 25\% declaró no tener jurisdicción. En el 1\% de los casos se decidió que el reclamo carecía manifiestamente de mérito. Centro Internacional de Arreglo de Diferencias Relativas a Inversiones, “The ICSID Caseload- Statistics (Issue 2014-2)”. Disponible en: https://CIADI.worldbank.org/apps/CIADIWEB/resources/Documents/ CIADI\%20Web\%20Stats\%202014-2\%20\%28English\%29.pdf. Tabla 8a.

2. La primera decisión que el tribunal arbitral debe tomar en la audiencia de sustanciación es la relativa a su competencia, según reza el artículo 22 de la Ley de Arbitraje y Mediación.

3. Como explica VÉsCOvi, los presupuestos procesales son "los requisitos necesarios para que pueda constituirse un proceso válido, o una relación procesal válida”. E. VÉsCOvi, Teoría general del proceso, 2 da ed. actualizada, Bogotá: Temis, 2006, p. 81. En realidad, los presupuestos procesales pueden no afectar la validez del proceso, pero sí ser necesarios para poder dictar una sentencia que se pronuncie sobre el fondo, como ocurre con la legitimación en la causa. 
Cuantificar los daños puede ser muy engorroso, dado que es una labor inherentemente económica ${ }^{4}$, en la que los aspectos jurídicos tienen relativamente menos importancia. La práctica judicial ecuatoriana, que debería servir de referente, nos ha dado varios ejemplos de cómo no realizar una valoración de daños adecuada ${ }^{5}$. La situación en el arbitraje de inversión, como explica Ripinsky, tampoco es la ideal, ya que hay la impresión de que no hay un enfoque sistemático y coherente para aproximarse a las cuestiones de compensación ${ }^{6}$, lo que genera incertidumbre sobre el resultado de las controversias ${ }^{7}$.

Pero no hay duda de que la cuantificación de los daños es muy importante. Por ejemplo, hay arbitrajes de inversión que involucran cuantías

4. G. SIDAK, "The Use of Economists as Arbitrators or Tribunal-Appointed Experts", p. 11.

5. Un ejemplo tristemente célebre es la sentencia de 17 de diciembre de 2007 dictada por el juez segundo de lo civil de Pichincha en el juicio entre Nueva Industria Farmacéutica Ecuatoriana NIFA S.A. (que después pasó a llamarse Prophar S.A.) y Merck, Sharp \& Dohme (en adelante, “caso Merck"), en la que se otorgó a la actora una indemnización de USD 200 millones sin dar explicación plausible alguna de cómo realizó esa valoración. Según reza la parte relevante del fallo: "La compañía actora ha sufrido dos clases de perjuicios: En primer término, ha de invertir tiempo y dinero para llevar adelante las infructuosas negociaciones con la Compañía demandada ya que incluso hay prueba en el proceso que los representantes de la demandada han debido viajar al exterior para mantener reuniones con los personeros de la demandada. Por otro lado, al habérsele frustrado su programa de crecimiento, a través de los actos de engaño que sufrió y vi que buscaban impedir que hiciera competencia Merck Sharp [\&] Dohme (ínter American) [sic] Corporation ha dejado de recibir ingresos que pudo haber obtenido se hubiera contado con una planta industrial que contara con una mayor capacidad de producción. Para valorar los perjuicios se debe tener en cuenta no sólo la competencia que hubiere hecho a la demandada (esta [sic] mismo ha valorado los montos de las posibles pérdidas en ventas que le hubiere ocasionado la competencia de la actora), sino también la competencia que hubiera podido hacer a otras compañías que comercializa sus productos en el mercado farmacéutico. En Ecuador se comercializa productos farmacéuticos por un valor superior a los USD \$ 400000.000,00 valor que nos da idea del enorme volumen de ventas que existe en este mercado. De acuerdo con las proyecciones presentadas por Nueva Industria Farmacéutica Asociada S.A. (Nifa S.A.) a Merck Sharp \& Dohme (ínter American) [sic] Corporation para el año 2002 se habrían alcanzado el 16\% de participación en el mercado, lo que supone que podría haber alcanzado ventas cercanas o superiores a los USD $\$ 60000.000,00$. Todo este proceso se ha truncado las posibilidades de crecimiento se han visto dificultadas [sic] como consecuencia de los actos de engaño que la demandada sufrió. No resultaba desproporcionado determinar la existencia de un perjuicio millonario que se ha ocasionado a la Compañía actora como consecuencia directa de los actos de engaño realizadas por la Compañía demandada y que llevaron al establecimiento de una barrera para el ingreso de Nueva Industria Farmacéutica Asociada S.A. (Nifa S.A.) con sus nuevos productos al mercado lo que estuvo originado por el deseo de la compañía demandada de evitar la competencia, que en sus propias palabras erosionan su participación en el mercado. Por las consideraciones expuestas, ADMINISTRANDO JUSTICIA EN NOMBRE DE LA REPUBLICA Y POR AUTORIDAD DE LA LEY, se acepta la demanda planteada por Nueva Industria Farmacéutica Asociada S.A (Nifa S.A.) en contra de Merck Sharp \& Dohme (ínter American) [sic] Corporation y rechazándose las excepciones planteadas por la demandada se dispone que esta pague a la actora, a título de indemnización por los daños y perjuicios que le ha ocasionado la suma de doscientos millones de dólares de los Estados Unidos de América (USD \$200000.000,00) más los intereses a partir de la presente fecha hasta la total cancelación de la indemnización [...]”.

6. A lo largo de este trabajo utilizaremos el término "compensación" como un sinónimo de "resarcimiento". No debe confundírsela, sin embargo, con la compensación como modo de extinguir las obligaciones.

7. S. RIPINSKY, "Assessing Damages in Investment Dispuntes: Practice in search of perfect", en: Journal of World Investment and Trade, Vol. 10, No. 1, 2009, p. 1. 
superiores al producto interno bruto de algunos países ${ }^{8}$. En esos casos, pequeñas diferencias en la metodología de valoración pueden suponer variaciones de decenas de millones de dólares en la condena. La valoración de daños también es importante porque hay controversias que yacen esencialmente en determinar el valor de un activo, como sucede en los casos de expropiación?.

Eso explica la tendencia cada vez mayor, tanto en el arbitraje doméstico como en el internacional, a que los tribunales arbitrales expliciten sus fundamentos para determinar el quantum del resarcimiento debido al actor ${ }^{10}$.

Son varios los beneficios para los practicantes del arbitraje de estudiar los métodos de valoración de daños. Primero, la determinación previa de los perjuicios ayudará a establecer si se justifica iniciar un arbitraje, ya que así puede conocer a cuánto podría aspirar el potencial reclamante. Con ese análisis preliminar se sabrá si se justifica entablar una demanda arbitral, con todos los costos que representa ${ }^{11}$.

Segundo, porque puede ayudar a alcanzar un acuerdo negociado. Si ambas partes realizan una valoración adecuada de los daños, será mucho más probable que puedan llevar a cabo una negociación fructífera. Cada parte tendrá una idea de qué es lo que puede esperar en caso de que el tribunal dirima la controversia. Así también se sabrá cuán atractiva es para la otra parte la alternativa de continuar con el arbitraje. Por el contrario, si una de las partes tiene aspiraciones no fundamentadas en una valuación seria, la otra seguramente preferirá esperar la decisión del tribunal ${ }^{12}$.

8. Por ejemplo, la condena impuesta a Rusia en el caso conocido como Yukos, que consistió en tres arbitrajes paralelos (en adelante, "caso Yukos"), de más de 50 mil millones, es superior al producto interno bruto de 2013 de Nicaragua, Honduras, Chad y Belice combinados. Ver: Hulley Enterprises Limited (Cyprus) vs. Federación Rusa, Caso CPA No. AA 228, laudo de 18 de julio de 2014; Yukos Universal Limited (Isle of Man) vs. Federación Rusa, Caso CPA No. AA 227, laudo de 18 de julio de 2014: y, Veteran Petroleum Limited (Cyprus) vs. Federación Rusa, Caso CPA No. AA 229, laudo de 18 de julio de 2014.

9. Por ejemplo, Guaracachi America, Inc. y Rurelec PLC vs. Estado Plurinacional de Bolivia, Caso CPA No. 201117; Tidewater Investment SRL vs. República Bolivariana de Venezuela, Caso CIADI ARB/10/25.

10. Mobil Corporation, Venezuela Holdings, B.V. et al. vs. República Bolivariana de Venezuela, Caso CIADI No. $\mathrm{ARB} / 07 / 27$, Anexo 1; en el orden local, un buen ejemplo es el laudo de 12 de noviembre de 2012 dictado por el tribunal arbitral independiente para el caso Juan Carlos Chaparro en contra del Estado ecuatoriano, dentro del arbitraje ordenado por la Corte Interamericana de Derechos Humanos, pp. 125 y ss.

11. Por ejemplo, los costos del arbitraje en el caso Yukos, según la estimación del tribunal, ascendieron a $8,440,000$ euros. Los costos de los abogados de los actores ascendieron a aproximadamente 80 millones de dólares y los de los abogados de la defensa, a aproximadamente 27 millones. Yukos Universal Limited (Isle of Man) v. Federación Rusa, Caso CPA No. AA 227, pp. 1866, 1873 y 1874

12. G. SIDAK, "The Use of Economists as Arbitrators or Tribunal-Appointed Experts", p. 1. 
Tercero, porque las partes buscarán presentar una estimación de daños que favorezca a sus intereses ${ }^{13}$. La práctica arbitral —especialmente en el arbitraje internacional- demuestra que los expertos tienen pocos reparos en introducir supuestos en sus análisis con el fin de justificar valoraciones que convengan a los intereses de sus respectivos clientes. Es tarea de los abogados y de los árbitros poder identificar esas racionalizaciones, entender en qué consisten y en qué medida afectan a la cuantificación de los daños.

Con ese antecedente, el objetivo de este trabajo es hacer una muy breve introducción a los métodos de valoración de daños. No se pretende presentar un análisis exhaustivo sobre las técnicas de valoración ni tampoco dar respuesta a todos los temas que tienen relevancia en ese respecto. Sencillamente se busca exponer algunas nociones que, en nuestro sentir, pueden ser de auxilio para los tribunales y para las partes al asumir muchas veces la compleja labor de determinar el quantum de los daños.

Para el efecto nos serviremos del siguiente esquema: en primer lugar explicaremos cuál es el objetivo del régimen de responsabilidad civil; luego nos referiremos a los principales métodos de valoración de daños; más adelante expondremos algunas consideraciones jurídicas que pueden ser relevantes al calcular el resarcimiento debido al actor; y, finalmente, expondremos nuestras conclusiones.

\section{Objetivo del régimen de daños}

Como explica Kantor, una de las preguntas que se debe responder al determinar el estándar de compensación aplicable es qué es lo que se busca con él14: ¿Se debe dejar al actor en la posición en la que habría estado en ausencia del ilícito o en la situación en la que estaba antes de realizar su inversión? Yendo más allá, ¿se debe buscar resarcir a la víctima o sancionar al responsable del daño?

13. Ibídem, p. 2.

14. M. KANTOR, Valuation for Arbitration, Kluwer Law International, 2008, p. 6. 
El propósito esencial del régimen de responsabilidad civil de la mayoría de ordenamientos jurídicos es reparar el daño causado a la víctima, lo que quiere decir dejarla en la posición en la que habría estado en ausencia del ilícito ${ }^{15}$. Lo mismo ocurre con nuestro ordenamiento. El objetivo de nuestro Derecho de daños no es sancionar al responsable de la infracción, sino resarcir al perjudicado. Es por eso que el régimen de reparación de daños no puede convertirse en un "filón de enriquecimiento"16.

En materia de actos internacionalmente ilícitos, la compensación se basa en el principio afirmado por la Corte Permanente de Justicia Internacional en caso de la fábrica Chorzów, en el que se estableció que la compensación debe, en la medida de lo posible, eliminar todas las consecuencias del acto ilícito y restablecer la situación que, con toda probabilidad, habría existido si dicho acto ilícito no se hubiera cometido ${ }^{17}$.

En el contexto del arbitraje de inversión, generalmente lo que se busca determinar es el valor justo de mercado de un activo ${ }^{18}$. El valor justo de mercado se define como el precio al que el activo sería vendido entre un comprador y un vendedor hipotéticos e independientes, si tuvieran información suficiente sobre el activo e hicieran la transacción de manera prudente y sin coacción de ningún tipo ${ }^{19}$. Como dijo el tribunal de Compañía del Desarrollo de Santa Elena vs. Costa Rica, el valor justo de mercado es lo que un comprador hipotético estaría dispuesto a pagar a un vendedor hipotético ${ }^{20}$. Según Dolzer, "compensation for expropriation, as expressed in the investment's fair market value, is an

15. I. MARBOE, Calculation of Compensation and Damages in International Investment Law, Oxford University Press, 2009, p. 27.

16. Fallo de la Primera Sala de lo Civil y Mercantil de la Corte Suprema de Justicia dentro del expediente de casación 79, en el juicio 43-2002, publicado en el Registro Oficial 87 de 22 de mayo de 2003. Además, como sostuvo la misma Sala en su fallo dictado dentro del expediente 501, en el recurso de casación 239-2000, publicado en el Registro Oficial 284 de 14 de marzo de 2001, "el deber es de reparar el daño y nada más que el daño en su integridad, ya que tampoco constituye fuente de enriquecimiento para la víctima del ilícito”.

17. Como dijo la Corte, "Reparation must, as far as possible, wipe out all the consequences of the ilegal act and re-establish the situation wich would, in all probability, have existed if that act had not been commited". Citado por J. BAKER, en: "The Different Forms of Reparation: Compensation", en: The Law of International Responsibility, James Crawford, Alain Pellet y Simon Olleson, (Dir.), Oxford University Press, 2010, p. 600.

18. Como explica MARBOE, "The standard of 'fair market value' as the basis for calculating the amount of compensation appears in many BITs and model BITs". I. MARBOE. Calculation of Compensation and Damages in International Investment Law, Oxford University Press, 2009, p. 49.

19. M. KANTOR, Valuation for Arbitration. Kluwer Law International, 2008, p. 30.

20. Compañía del Desarrollo de Santa Elena SA vs. Costa Rica, Caso CIADI ARB/96/1, laudo de 17 de febrero de 2000, p. 73, citado por I. MARBOE. Calculation of Compensation and Damages in International Investment Law, Oxford University Press, 2009, p. 51. 
objective standard that looks at the amount that a willing buyer would normally pay to a willing seller in a free transaction, at arm's length" ${ }^{21}$. Ese estándar de compensación no busca enriquecer al perjudicado, sino otorgarle un monto equivalente al que habría obtenido si hubiera vendido el activo en cuestión en el mercado.

Por lo tanto, al cuantificar los daños no se puede perder de vista que el resarcimiento no puede dejar a la víctima en una situación más favorable que la que tenía antes del ilícito.

\section{Métodos de valoración de daños}

Con esos antecedentes, a continuación revisaremos tres de los principales métodos de valoración de daños. El primero, el método de flujo de fondos descontado (discounted cash flow o "DCF"), es el método intrínseco más importante. Luego nos referiremos en general a los métodos de valoración relativa, que son los que se basan en el valor de activos comparables. Más tarde haremos una revisión muy superficial del método de valoración con base en el valor de los activos. Concluiremos refiriéndonos a dos temas de interés, como son la determinación de la fecha de valoración y el escenario contrafáctico.

\subsection{Los métodos intrínsecos (y el método de flujo de fondos descontado)}

Los métodos intrínsecos determinan el valor de un activo con base en los flujos de efectivo que ese activo vaya a generar. Dejando todo lo demás igual, mientras mayores sean los flujos que un activo vaya a recibir y menor sea su riesgo, su valor será mayor.

Los métodos intrínsecos nos ayudan a establecer cuál es el valor presente neto de un proyecto. ¿Por qué necesitamos establecer el valor presente neto? Porque el valor del dinero cambia a lo largo del tiempo. Dos flujos de efectivo no pueden ser comparados si ocurren en momentos distintos. Para poder comparar esos flujos, como explicaremos más adelante, requerimos

21. R. IDOLZER y C. SCHEURER, Principles of International Investment Law, 2da ed., Oxford University Press, 2012, p. 297. 
hacer uso de una herramienta denominada "tasa de descuento". De allí que este método se denomine "flujo de fondos descontados".

La variación del valor del dinero en el tiempo se debe a tres factores:

- Primero, a que la capacidad adquisitiva del dinero se ve afectada por el paso del tiempo;

- Segundo, a que los flujos futuros están expuestos a un riesgo; y,

- Tercero, a que las personas prefieren el consumo presente al consumo futuro.

El DCF es el tipo más popular de los métodos valoración intrínsecos ${ }^{22}$. A continuación revisaremos los pasos que se debe seguir para aplicar ese método.

\subsubsection{Cálculo de los flujos libres de efectivo}

El primer paso para valuar un activo aplicando el método DCF consiste en determinar cuáles van a ser las entradas y salidas marginales de efectivo y establecer cuándo van a ocurrir. Para ello podemos servirnos de una línea de tiempo. Supongamos que un proyecto va a generar de ingresos incrementales de USD 100 y significará erogaciones de USD 75 cada año durante seis años. Los flujos libres de efectivo serían los siguientes:

\begin{tabular}{|c|c|c|c|c|c|c|}
\hline & Año 1 & Año 2 & Año 3 & Año 4 & Año 5 & Año 6 \\
\hline $\begin{array}{c}\text { Entradas } \\
\text { de efectivo } \\
\text { (EE) }\end{array}$ & USD 100 & USD 100 & USD 100 & USD 100 & USD 100 & USD 100 \\
\hline $\begin{array}{c}\text { Salidas de } \\
\text { efectivo } \\
\text { (SE) }\end{array}$ & USD 75 & USD 75 & USD 75 & USD 75 & USD 75 & USD 75 \\
\hline $\begin{array}{c}\text { Flujos } \\
\text { libres (FL } \\
\text { EE-SE) }\end{array}$ & USD 25 & USD 25 & USD 25 & USD 25 & USD 25 & USD 25 \\
\hline
\end{tabular}

22. M. KANTOR, Valuation for Arbitration, Kluwer Law International, 2008, p. 
Cabe hacer algunas acotaciones. La primera es que debemos analizar los flujos netos, es decir la diferencia entre las entradas y las salidas de efectivo. Al realizar una valoración no podemos basarnos únicamente en los ingresos pronosticados del proyecto. Hay que tomar en cuenta también las salidas de efectivo que se vaya a realizar. Por lo tanto, si un actor pretendiera ser resarcido por las "ventas" que no pudo efectuar, el monto de los perjuicios sufridos por él necesariamente sería inferior al monto de dichas ventas, ya que también deberían tomarse en cuenta los costos en los que habría tenido que incurrir.

La segunda acotación es que no se puede sumar los flujos netos para determinar cuál es el valor de ese proyecto el día de hoy. Ya se explicó que flujos que ocurren en distintos momentos no pueden compararse entre sí. Primero sería necesario descontarlos haciendo uso de la tasa de descuento, un concepto que revisaremos más adelante.

La tercera acotación es que nos interesa calcular las entradas y salidas de efectivo y no necesariamente la utilidad contable. La utilidad contable no es un referente útil porque muchos ingresos y egresos contables no suponen una entrada o salida de dinero ${ }^{23}$. Es por eso que el cálculo de los flujos libres de efectivo no puede tomar como referencia, sin más, los estados de pérdidas y ganancias o las declaraciones de impuestos, ya que esos documentos consideran como ingresos o egresos a operaciones que pueden no implicar la entrada o salida de efectivo, respectivamente.

Además, como quedó dicho, nos interesan los flujos marginales o incrementales. Esto tiene una relevancia muy grande al valorar los daños, ya que no puede concederse al reclamante sino los beneficios que habría recibido en ausencia del ilícito, es decir en el escenario contrafáctico. Nos referiremos al escenario contrafáctico más adelante.

Finalmente, hay que prestar atención a qué es lo que se está valorando. Si se está determinando el valor de la firma en su totalidad, incluyendo

23. Por ejemplo, la depreciación, que es un egreso contable, no supone una salida de efectivo. Por ese motivo, sería un error incluir los montos de depreciación en el cálculo de los flujos libres de efectivo. Un aumento en el capital de trabajo puede significar un aumento en la utilidad contable pero puede no involucrar una entrada de efectivo. Del mismo modo, los gastos de capital (conocidos como capex) no se registran contablemente pero sí suponen una salida de efectivo, por lo que sería necesario tomarlos en cuenta al determinar los flujos libres de efectivo. 
sus pasivos y su capital, deberemos tomar en consideración unos flujos de efectivo distintos a los que usaríamos si estuviéramos valuando únicamente el capital.

\subsubsection{Tasa de crecimiento}

El segundo paso para determinar el valor presente neto de un proyecto consiste en determinar la tasa de crecimiento de las entradas y salidas de efectivo. Es uno de los aspectos más importantes dentro de la valoración ${ }^{24}$.

El pronóstico exacto de las variaciones de los flujos es imposible porque está sujeto a un número de variables infinito. Sin embargo, en ciertos casos podemos pronosticar la tasa de crecimiento extrapolando la información histórica ${ }^{25}$.

En nuestro ejemplo, supongamos que el proyecto generó USD 100 durante el primer año y que los ingresos y egresos crecieron creciendo a razón del $10 \%$ durante 3 años.

\begin{tabular}{|c|c|c|c|c|c|c|}
\hline & Año 1 & Año 2 & Año 3 & Año 4 & Año 5 & Año 6 \\
\hline $\begin{array}{c}\text { Entradas } \\
\text { de efectivo } \\
\text { (EE) }\end{array}$ & USD 100 & USD 110 & USD 121 & USD 133.1 & ¿? & ¿? \\
\hline $\begin{array}{l}\text { Salidas de } \\
\text { efectivo } \\
\text { (SE) }\end{array}$ & USD 75 & USD 82.5 & USD 90.75 & USD 99.82 & ¿? & ¿? \\
\hline $\begin{array}{c}\text { Flujos } \\
\text { libres (FL= } \\
\text { EE-SE) }\end{array}$ & USD 25 & USD 27.5 & USD 30.25 & USD 33.28 & ¿? & ¿? \\
\hline
\end{tabular}

Con esa información podríamos inferir que los ingresos en los años 5 y 6 seguirán creciendo a razón del $10 \%{ }^{26}$ :

24. A. Damodaran, Investment Valuation. Tools and Techniques for Determining the Value of Any Asset, Wiley Finance. 3ra. ed. Nueva Jersey: 2012, p. 271.

25. Ibídem.

26. Sin embargo, hay que tener cuidado. Es probable que una empresa no mantenga el ritmo de crecimiento de los primeros años de manera indefinida. Una vez que la firma haya madurado, su tasa de crecimiento seguramente 


\begin{tabular}{|c|c|c|c|c|c|c|}
\hline & Año 1 & Año 2 & Año 3 & Año 4 & Año 5 & Año 6 \\
\hline $\begin{array}{c}\text { Entradas } \\
\text { de efectivo } \\
\text { (EE) }\end{array}$ & USD 100 & USD 110 & USD 121 & USD 133.1 & $\begin{array}{c}\text { USD } \\
146.41\end{array}$ & $\begin{array}{c}\text { USD } \\
161.05\end{array}$ \\
\hline $\begin{array}{c}\text { Salidas de } \\
\text { efectivo } \\
\text { (SE) }\end{array}$ & USD 75 & USD 82.5 & USD 90.75 & USD 99.82 & USD & $\begin{array}{c}\text { USD } \\
109.80\end{array}$ \\
\hline $\begin{array}{c}\text { Flujos } \\
\text { libres (FL= } \\
\text { EE-SE) }\end{array}$ & USD 25 & USD 27.5 & USD 30.25 & USD 33.28 & USD 36.60 & USD 40.26 \\
\hline
\end{tabular}

\subsubsection{Tasa de descuento y el factor de descuento}

El tercer paso para determinar el valor presente neto consiste en determinar la tasa de descuento. La tasa de descuento es la herramienta que nos permite transportar un flujo de efectivo a distintos momentos en el tiempo. Es por eso que, como explica KanToR, "selecting the proper discount rate is central to a DCF valuation" 27 .

¿Y qué es la tasa de descuento? Es el rendimiento mínimo que los inversores esperarían por invertir en un activo. Un potencial inversor exigirá un rendimiento mayor mientras mayor sea el riesgo del activo. Es por eso que decimos que los inversores tienen aversión al riesgo. La aversión al riesgo explica que activos más riesgosos tengan una tasa de descuento más alta que activos más seguros.

Una vez que hemos determinado la tasa de descuento sabremos, por ejemplo, cuánto valen el día de hoy USD 100 que deben ser pagados en un año. Basta con que descontemos ese flujo utilizando la tasa de descuento para encontrar su valor presente.

La tasa de descuento puede tener una importancia sumamente grande en la valuación. KANTOR lo explica con el siguiente ejemplo. Supongamos que

será menor. Por lo tanto, al calcular el valor terminal de una empresa, seguramente será necesario hacer una proyección más conservadora de dicha tasa de crecimiento.

27. M. KANTOR, Valuation for Arbitration, Kluwer Law International, 2008, p. 139. 
un proyecto generará USD 10 millones al año durante 10 años. Si aplicamos una tasa de descuento del $33.7 \%$, el valor presente neto de ese proyecto será de USD 28.05 millones. En cambio, si aplicamos una tasa de descuento del 8.5\%, el valor presente neto será USD 65.61 millones $^{28}$.

En Occidental, por ejemplo, el tribunal concluyó que el valor presente neto de los flujos generados por la demandante hasta la fecha de valoración fue de aproximadamente USD 2,360 millones ${ }^{29}$. Para obtener ese resultado aplicó una tasa de descuento del $12 \%{ }^{30}$. Si el tribunal hubiera aplicado una tasa de descuento del 15\%, que es la tasa que el experto de Ecuador consideró aplicable en un principio ${ }^{31}$, el valor de los daños habría sido menor en al menos 60 millones de dólares ${ }^{32}$.

En nuestro ejemplo, si la tasa del descuento fuera del 15\%, los resultados serían como sigue:

\begin{tabular}{|c|c|c|c|c|c|c|}
\hline & Año 1 & Año 2 & Año 3 & Año 4 & Año 5 & Año 6 \\
\hline $\begin{array}{l}\text { Entradas de } \\
\text { efectivo (EE) }\end{array}$ & USD 100 & USD 110 & USD 121 & USD 133.1 & $\begin{array}{c}\text { USD } \\
146.41\end{array}$ & $\begin{array}{c}\text { USD } \\
161.05\end{array}$ \\
\hline $\begin{array}{l}\text { Salidas de } \\
\text { efectivo (SE) }\end{array}$ & USD 75 & USD 82.5 & USD 90.75 & USD 99.82 & $\begin{array}{c}\text { USD } \\
109.80\end{array}$ & $\begin{array}{c}\text { USD } \\
120.78\end{array}$ \\
\hline $\begin{array}{l}\text { Flujos libres } \\
(\mathrm{FL}=\mathrm{EE}-\mathrm{SE})\end{array}$ & USD 25 & USD 27.5 & USD 30.25 & USD 33.28 & USD 36.60 & USD 40.26 \\
\hline $\begin{array}{l}\text { Tasa de des- } \\
\text { cuento (TD) }\end{array}$ & $15 \%$ & $15 \%$ & $15 \%$ & $15 \%$ & $15 \%$ & $15 \%$ \\
\hline $\begin{array}{l}\text { Factor de des- } \\
\text { cuento }^{33}(\mathrm{FD}= \\
\quad(1+\mathrm{TD}) \mathrm{n})\end{array}$ & 1.15 & 1.32 & 1.52 & 1.75 & 2.01 & 2.31 \\
\hline $\begin{array}{l}\text { Valor presente } \\
\text { de los flujos } \\
\text { libres (FL/FD) }\end{array}$ & $\begin{array}{l}\text { USD } \\
21.74\end{array}$ & $\begin{array}{l}\text { USD } \\
20.79\end{array}$ & USD 19.89 & USD 19.03 & USD 18.20 & USD 17.41 \\
\hline
\end{tabular}

28. Ibídem, p. 140.

29. Sin tomar en consideración la reducción en la condena por la culpa compartida de las demandantes, que fue del 25\%. Occidental Petroleum Corporation y Occidental Exploration and Production Company vs. Ecuador, Caso CIADI No. ARB/06/11, laudo de 5 de octubre de 2012, p 687.

30. Ibídem, p 764 .

31. Ibídem, p. 760 .

32. El valor presente neto de esos flujos no habría superado los USD 2.298 millones de dólares.

33. El factor de descuento es el valor por el que hay que dividir los flujos libres para obtener su valor presente. Depende de la tasa de descuento y del número de períodos. Mientras más lejano en el futuro esté un pago, mayor será el factor de descuento. 
Nótese que, conforme va pasando el tiempo, el valor presente de los flujos va disminuyendo. Mientras más lejano en el futuro esté un flujo, menor será su valor el día de hoy.

\subsubsection{1. ¿Cómo calcular la tasa de descuento?}

Los ejemplos anteriores dejan entrever cuánta importancia tiene calcular adecuadamente la tasa de descuento. Es por eso que escoger la metodología correcta resulta fundamental para realizar una valoración precisa.

Existen varios métodos para calcular la tasa de descuento. El más popular quizás sea el modelo de valoración de activos de financieros (capital asset pricing model o CAPM por sus siglas en inglés).

La idea que subyace al CAPM es muy sencilla: mientras mayor sea el riesgo de un activo que no pueda eliminarse a través de la diversificación, mayor será el rendimiento que los inversores esperarán para invertir en él. Es decir que el CAPM se basa en el riesgo no diversificable de un activo ${ }^{34}$. Como explica Kantor, "[t]he idea underlying that approach is to isolate the risks attributable to the particular business activity in which the company is engaged"35.

Para calcular la tasa de descuento aplicando el CAPM se necesita determinar lo siguiente:

- La tasa libre de riesgo;

- La prima de riesgo por invertir en el mercado; y,

- El coeficiente beta $(\beta)$, que representa la relación entre el riesgo de un activo y el riesgo del mercado ${ }^{36}$.

34. El riesgo no diversificable, como su nombre lo indica, es el que no puede eliminarse a través de la diversificación. Un ejemplo de un riesgo no diversificable es un terremoto o una devaluación de la moneda. Si ocurre un terremoto, todas las firmas se verán afectadas por igual. En cambio, el riesgo diversificable puede reducirse si se adiciona activos adicionales al portafolio.

35. M. KANTOR, Valuation for Arbitration, Kluwer Law International, 2008, p. 162. El mismo autor explica que este método "attempts to measure the difference between the equity risk of the particular assets held by the company in question (say, power plants) and the equity risk of investing in a hypothetical portfolio of diversified assets". M. KANTOR, Valuation for Arbitration, Kluwer Law International, 2008, p. 162.

36. El coeficiente beta se obtiene al dividir la covarianza entre los rendimientos del activo valuado y los rendimientos del mercado por la varianza del rendimiento del mercado. S. MYERS y R. BREALEY, Principles of Corporate Finance, 6ta edición. Mc. Graw Hill, 2000, p. 176. 
El CAPM no está exento de críticas, principalmente porque parte de supuestos que no son verosímiles ${ }^{37}$, pero su principal ventaja es que resulta relativamente simple de entender y de aplicar.

\subsubsection{2. ¿Cuál es la tasa de descuento que se debe usar?}

La tasa de descuento que resulte aplicable variará dependiendo de qué es lo que se esté valuando. Cuando se esté valorando una firma en su totalidad, incluyendo su patrimonio y su deuda, será necesario aplicar una tasa de descuento que refleje el peso ponderado de cada fuente de financiamiento, lo que se conoce como el Coste Promedio Ponderado de Capital (Weighted Average Cost of Capital o WACC).

En cambio, si se está valuando únicamente el capital de una firma, será necesario aplicar una tasa de descuento que refleje el riesgo del capital únicamente $^{38}$.

\subsubsection{Sumatoria de los flujos libres de efectivo}

El último paso para determinar el valor de un activo consiste en sumar todos los flujos descontados. Como explicamos más arriba, para poder comparar dos flujos necesitamos que estén en un mismo momento y la herramienta que utilizamos para hacerlo es la tasa de descuento.

Una vez que hemos traído todos los flujos de efectivo a valor presente, nos es posible sumarlos. Esa suma nos dará el valor presente neto de ese proyecto.

Así, en nuestro ejemplo, el valor presente neto del proyecto sería de USD 117.05. Para obtener ese resultado simplemente sumamos el valor presente de los flujos de cada año:

\begin{tabular}{|c|c|c|c|c|c|c|c|}
\hline & Año 1 & Año 2 & Año 3 & Año 4 & Año 5 & Año 6 & Total \\
\hline $\begin{array}{c}\text { Valor presente de } \\
\text { los flujos libres } \\
\text { (FL/FD) }\end{array}$ & USD & USD & USD & USD & USD & USD & USD \\
\hline
\end{tabular}

37. El CAPM asume que no hay costos de transacción, que todos los activos pueden ser comerciados, que todos los inversores tienen acceso a la misma información y que todos los activos son infinitamente divisibles, lo que quiere decir que para los inversores no es costoso diversificar tanto como sea posible. Como consecuencia de esos supuestos, el CAPM asume que cada inversor tiene al menos una pequeña parte de cada activo de la economía. A. DAMODARAN, Investment Valuation. Tools and Techniques for Determining the Value of Any Asset, Wiley Finance. 3ra. ed. Nueva Jersey, 2012, p. 68.

38. Ibídem, p. 266. 


\subsubsection{Limitaciones al método DCF}

El método DCF no ha estado exento de críticas. Ciertos tribunales han considerado que no resulta aplicable cuando la firma analizada no ha operado el tiempo suficiente como para poder realizar un pronóstico de sus ganancias futuras ${ }^{39}$. Se ha considerado que el método analiza una amplia gama de elementos "inherentemente especulativos" que tienen un impacto significativo en el resultado, por lo que puede ser preferible usar metodologías alternativas ${ }^{40}$. Según KANTOR, "If the enterprise being valued is not a 'going concern,' investment tribunals are unwilling to project forward for estimated revenues and expenses of operation"41.

Como explicó el tribunal en Metalclad,

Normalmente, el valor justo de mercado de una empresa en actividad que ha tenido una trayectoria de rentabilidad puede basarse en la estimación de las ganancias futuras, sujetas a un análisis de la actualización de los flujos de fondos. [...] Sin embargo, cuando una empresa no ha estado en actividad el tiempo suficiente para establecer su desempeño o no ha producido beneficios, las ganancias futuras no pueden utilizarse para determinar el valor corriente ni el valor justo de mercado ${ }^{42}$.

En algunos de los casos en los que el método DCF se ha considerado inaplicable, los tribunales han resuelto otorgar al reclamante un resarcimiento equivalente a los gastos que realizó con motivo de su inversión, más una tasa de interés que represente un retorno "razonable". En ese caso, como explica KANTOR, "many tribunals will either award the Adjusted Book Value $(A B V)$ of the enterprise or order recovery of the 'sunk costs' (i.e., the invested capital) together with a reasonable rate of return"43.

\footnotetext{
39. Southern Pacific Properties (Middle East) Limited vs. Egipto, Caso CIADI No. ARB/84/3, p. 188.

40. Comisión de Derecho Internacional de las Naciones Unidas, Draft Articles on Responsibility of States for Internationally Wrongful Acts, with Commentaries, aprobados por la Asamblea General de las Naciones Unidas en su Quincuagésimo sexto periodo de sesiones, p. 103.

41. M. KANTOR, Valuation for Arbitration, Kluwer Law International, 2008, p. 90.

42. Metalclad Corporation v. Estados Unidos Mexicanos, Caso CIADI No. ARB (FA)/97/1, pp. 119, 120.

43. M. KANTOR, Valuation for Arbitration, Kluwer Law International, 2008, p. 90.
} 
Consideramos que las críticas al método DCF son infundadas. En nuestra opinión, no hay limitación metodológica alguna que impida aplicar el método DCF a firmas jóvenes o a proyectos nuevos. Sin embargo, la explicación del porqué deberá ser tratada en otra oportunidad ${ }^{44}$.

\subsection{Métodos relativos}

Mientras que los métodos intrínsecos encuentran el valor de un activo según sus flujos de efectivo, su tasa de crecimiento y su riesgo, los métodos relativos se basan en el valor de otros activos comparables. En la valoración relativa, el objetivo es valuar activos basándonos en cómo esos activos son valorados en el mercado ${ }^{45}$.

Los métodos relativos son utilizados con mayor frecuencia en la práctica. Cuando uno busca adquirir un vehículo o un departamento, por ejemplo, determina el precio de esos bienes tomando como referencia el precio que tienen bienes similares.

Los tres pasos esenciales en la valoración relativa son: i) encontrar activos comparables, ii) encontrar un estándar común (es decir, un múltiplo) entre esos activos para poder compararlos y iii) realizar los ajustes por las diferencias que existan entre dichos activos al comparar esos valores estandarizados ${ }^{46}$.

\subsubsection{Cómo encontrar las comparables}

El aspecto más contencioso de este método de valoración quizás sea determinar qué activos son comparables. ¿Puede compararse una concesión petrolera a una concesión minera? ¿Puede compararse un departamento en Quito a uno en Rumiñahui? ¿Son similares el Nuevo Aeropuerto Internacional de Quito y el aeropuerto de Heathrow, en Londres?

El problema central que se enfrenta al encontrar comparables es que no hay dos activos que sean exactamente iguales: "in the real world of arbitration,

44. Ver, por ejemplo, M. KANTOR, Valuation for Arbitration, Kluwer Law International, 2008, pp. 94 y ss.

45. A. DAMODARAN, Investment Valuation. Tools and Techniques for Determining the Value of Any Asset, Wiley Finance, 3ra. ed. Nueva Jersey, 2012, p. 453.

46. A. Damodaran, The Little Book of Valuation: How to Value a Company, Pick a Stock and Profit, Wiley: Nueva Jersey, posiciones 733-743, versión Kindle. 
no other enterprise likely will be precisely comparable with the company at the heart of the dispute" ${ }^{37}$. Además, al escoger qué activos comparar, se está partiendo de ciertos supuestos que no se hacen explícitos, lo que representa una de las mayores desventajas de los métodos relativos.

$\mathrm{Al}$ determinar qué firmas son comparables, $\mathrm{KANTOR}^{48}$ sugiere tomar en cuenta una lista de factores, entre los que están: su tamaño, su ubicación geográfica, su estructura de capital, su naturaleza pública o privada ${ }^{49}$, etc. También debe prestarse atención a que las firmas en cuestión operen en mercados sujetos, en lo posible, al mismo riesgo.

\subsubsection{Qué (y cómo) comparar}

Una vez que se ha encontrado las comparables, es necesario determinar qué es lo que se va a comparar. Como explicamos, es necesario convertir los precios a valores estandarizados - llamados múltiplos-. DAMODARAN categoriza a los múltiplos dependiendo de si se refieren a las utilidades (earnings multiples), al valor en libros (book value multiples) o a los ingresos (revenue multiples). Un ejemplo de los múltiplos que se refieren a las utilidades es el conocido como $P E$ (price-earnings) ratio, que se obtiene al dividir el precio de la acción por sobre las utilidades por acción.

Por ejemplo, supongamos que queremos valuar una compañía, $\mathrm{X}$, que obtuvo USD 2 de utilidades por acción. Asumamos que las acciones de una compañía comparable, Y, valen USD 6 en el mercado y que obtuvieron USD 1,5 de utilidades por acción. El PE ratio de Y sería de 4 (USD 6/ USD 1,5). Así, el precio de cada acción de X sería de USD 8 (que se obtendría al multiplicar el PE ratio de $\mathrm{Y}$ por las utilidades por acción de $\mathrm{X}$ ).

La principal advertencia al escoger los múltiplos es que hay que asegurarse de estar comparando lo mismo. Por ejemplo, no es lo mismo comprar los ingresos antes de depreciación, impuestos e intereses de una firma conocido como EBITDA, (por sus siglas en inglés) con las utilidades de otra. Tampoco es lo mismo usar el $P E$ ratio pronosticado de una firma con el $P E$ histórico de otra.

47. M. KANTOR, Valuation for Arbitration, Kluwer Law International, 2008, p. 122.

48. Ibídem, p. 124.

49. Entendiéndose por compañía pública a aquella que cotiza en bolsa. 


\subsubsection{Ajustes}

Ya explicamos que es imposible encontrar dos activos idénticos. Es por eso que, una vez que se encontró las comparables y se estableció qué es lo que se debe comparar, es necesario realizar ajustes que reflejen las diferencias que existen entre los activos materia de la comparación.

Por ejemplo, si estuviéramos comparando dos compañías, una pública y una privada, habría que tomar en consideración que vender acciones de la primera sería mucho más sencillo que vender acciones de la segunda. La liquidez de las acciones de la primera, dejando todo lo demás igual, debe traducirse en un valor mayor, por lo que sería necesario hacer un ajuste en ese sentido.

\subsection{Métodos basados en el valor de los activos}

Esta categoría de métodos de valoración adopta un enfoque diferente al de los métodos que expusimos antes. Como explica Marboe, de acuerdo con este enfoque, el valor de los diferentes componentes de un activo determina su valor total ${ }^{50}$.

La primera variante de este método se enfoca en el valor de liquidación, es decir el precio al que los activos de la firma podrían ser vendidos en el mercado. La segunda se basa en el valor de reposición, en el que se determina cuánto costaría reemplazar todos los activos que tiene la firma a la fecha de valoración. La tercera se enfoca en el valor en libros: se utiliza la información contable de la propia firma para estimar cuánto valen sus $\operatorname{activos}^{51}$.

Las ventajas de este enfoque es que parece ser mucho más sencillo de aplicar y menos especulativo, ya que mira hacia el pasado y no hacia el futuro. Además, la evidencia para emplearlo suele estar disponible y no requiere de pronóstico alguno ${ }^{52}$.

50. I. MARbOE, Calculation of Compensation and Damages in International Investment Law, Oxford University Press, 2009, p. 127.

51. A. Damodaran, Investment Valuation. Tools and Techniques for Determining the Value of Any Asset, Wiley Finance, 3ra. ed. Nueva Jersey, 2012, p. 22.

52. I. MARBOE, Calculation of Compensation and Damages in International Investment Law, Oxford University Press, 2009, p. 127. 
Las desventajas son que muchos activos y pasivos pueden no estar adecuadamente reflejados en la contabilidad de una empresa. Además, este enfoque no considera el valor adicional que puede surgir de combinar varios activos, es decir sus sinergias, y por tanto el valor que tendría la firma en su conjunto ${ }^{53}$.

\subsection{Otros aspectos relevantes en la valoración}

Conviene revisar dos temas adicionales que se debe tener presente durante el proceso de valoración. El primero es el escenario contrafáctico (el "but-for scenario") y el segundo, la fecha de valoración.

\subsubsection{El escenario contrafáctico}

Al determinar el monto de los daños debe compararse la situación existente con el escenario que se habría presentado en ausencia del ilícito. El perjudicado por un ilícito no puede ser resarcido por daños que habría sufrido de todas maneras.

Es por eso que decimos que resulta necesario determinar el escenario contrafáctico. Al reclamante no se le puede otorgar una compensación sino por las desmejoras que hubiera sufrido comparándolas con la situación que habría tenido de no haber sufrido un ilícito.

Si se trata de los actos ilícitos de los Estados, como explica Marboe,

If the unlawful act of a State destroys or impairs long-term investments, it appears appropriate to measure the damage incurred by a projection of the future income after the breach and compare it with the hypothetical future income without the breach. The difference between those two scenarios is equal to the damage caused by the unlawful act ${ }^{54}$.

Ése fue uno de los temas más cuestionables en la valuación de daños del caso Merck, al que nos referimos líneas atrás. El juez otorgó al reclamante

53. Ibídem, p. 268.

54. Ibídem, p. 238. 
USD 200 millones sin hacer análisis alguno de cuál fue la situación del actor en el escenario contrafáctico, es decir cuánto fue lo que efectivamente ganó incluso después del ilícito. Otorgarle todo lo que habría recibido en el escenario contrafáctico habría significado enriquecerlo de manera injusta, ya que así el reclamante habría terminado en una situación mejor que la que hubiera tenido en ausencia del ilícito.

\subsubsection{La fecha de valoración}

También es necesario determinar cuál es la fecha de valoración. Como explica Marboe, la fecha de valoración desempeña un rol muy importante en la cuantificación de la compensación y los daños en el Derecho Internacional de las Inversiones ${ }^{55}$, lo que, en nuestra opinión, puede hacerse extensivo a nuestro ordenamiento.

Son dos las razones por las que es importante determinar la fecha de valoración. La primera es que el efecto de los daños acaecidos después de la fecha de valoración en el valor justo de mercado del activo, para efectos de la compensación, es distinto al que tiene antes de ese momento.

Supongamos que un activo es expropiado en 2012 y que, al tener lugar la expropiación, su valor era de USD 10 millones. Supongamos también que, inmediatamente después de la expropiación, el valor del activo aumenta en un $30 \%$ por factores exógenos. ¿Cuál debería ser el resarcimiento otorgado al inversor? Como explica KANTOR, el enfoque usual al calcular el monto del resarcimiento consiste en analizar los efectos del acto ilícito al momento de cometerse el daño (es decir, en la fecha de valoración) y obviar los daños que ocurran después ${ }^{56}$. Por tanto, la fecha de valoración es importante porque, por lo general, lo que suceda con el valor del activo después de la fecha de valoración no incidirá en el cálculo del resarcimiento debido al reclamante ${ }^{57}$.

55. Ibídem, p. 126.

56. M. KANTOR, Valuation for Arbitration, Kluwer Law International, 2008, p. 64.

57. Una excepción a esa regla fue la decisión dictada entro del caso ADC vs. Hungría. En ese caso, el tribunal decidió fijar como fecha de valoración la fecha del laudo y no la de la expropiación, para así otorgar a los inversores una compensación que tomó en consideración el aumento de valor de la inversión después de la fecha de la expropiación. Eso se debió, entre otras razones, a que el tribunal consideró que la expropiación que sufrieron los inversores fue ilegal al no cumplir los requisitos del tratado aplicable. El tribunal consideró que otorgar a los inversores el mayor valor posterior a la inversión era la manera de cumplir con el principio establecido en el caso Chorzów, al que nos referimos más arriba. ADC Affiliate Limited y ADC \& ADMC Management Limited vs. Hungría, Caso CIADI No. ARB/03/16, laudo de 2 de Octubre de 2005, pp. 496-499. Citado por M. KANTOR, Valuation for Arbitration, Kluwer Law International, 2008, p. 64. 
La segunda razón por la que es importante determinar la fecha de valoración es que el cálculo de los perjuicios después de la fecha de valoración es distinto al que aplica antes de ese momento.

Vimos que para determinar el valor presente de un proyecto usamos la tasa de descuento. En cambio, para calcular cuánto varía el monto de los perjuicios desde la fecha de valoración y el momento de dictarse el laudo hay que aplicar la tasa libre de riesgo, y no el costo de capital. Como explica KANTOR, "The interest rate used for bringing historical amounts forward will clearly not contain the same risk factors as the discount rate used to present value future amounts" 58.

Por ejemplo, asumamos que un activo iba a producir flujos positivos desde 2010 hasta 2020 y que fue expropiado en 2012. Supongamos también que la parte que vio su activo expropiado reclama su justo valor de mercado en un arbitraje y que el laudo es dictado en 2015.

La fecha de valoración de esa inversión sería el momento en que el activo fue expropiado, en 201259. Los flujos futuros, desde 2012 hasta 2020, tendrían que traerse a valor presente usando la tasa de descuento que resulte aplicable.

Al dictar su laudo en 2015, el tribunal tendría que decidir cómo resarcir al perjudicado por los perjuicios sufridos entre 2012 (cuando tuvo lugar la expropiación) y el momento de dictarse el laudo. Para hacerlo, es tan simple como que tiene que otorgar al reclamante la tasa de interés libre de riesgo sobre el monto del resarcimiento desde la fecha de valoración hasta el momento de dictarse el laudo. El tribunal cometería un grave error si utilizara el WACC, por ejemplo, para "transportar" esos perjuicios desde la fecha de valoración hasta el momento de dictarse el laudo.

58. KANTOR, Ibídem, p. 47.

59. Debe tomarse en cuenta que ciertos tratados bilaterales de protección de inversiones disponen que la fecha de valuación en el caso de expropiaciones debe ser el momento inmediatamente anterior al momento en el que se anunció la expropiación, para que así el efecto del anuncio de la expropiación no se vea reflejado en el monto de compensación que debe ser otorgado. 


\section{Consideraciones jurídicas}

Nuestro ordenamiento jurídico contiene una serie de reglas que inciden al determinar el resarcimiento que debe otorgarse a quien ha sufrido un daño. Eso quiere decir que la utilización de los métodos de valoración muchas veces no basta por sí misma y debe ser complementada con la aplicación de ciertas normas. Es más, hay casos en los que las normas jurídicas suplen por completo a toda metodología de valoración.

Por cuestiones de espacio nos limitaremos a enlistar únicamente algunas de esas cuestiones jurídicas, entre las que están: la causa del daño, la mora, las cláusulas penales, el deber de mitigar los daños y la culpa de la víctima.

\subsection{Causa del daño}

Atendiendo a su fuente, el daño puede ser contractual o extracontractual. El daño contractual es el que deriva del quebrantamiento de una obligación preexistente ${ }^{60}$. Ocurre, por ejemplo, cuando el comprador incumple con su obligación de pagar el precio en el tiempo y en la forma debida.

El daño extracontractual, por exclusión, es todo daño que no es contractual. Estamos en presencia de responsabilidad extracontractual cuando se ocasiona un daño que el perjudicado no está jurídicamente obligado a soportar y que no deriva del incumplimiento de una obligación preexistente. El daño extracontractual nace con ocasión de la comisión de delitos o cuasidelitos civiles.

Se ha cuestionado mucho la utilidad de someter cada tipo de responsabilidad a un régimen separado - $\mathrm{y}$ no siempre es sencillo distinguirlas en un caso concreto- . Sin embargo, la clasificación tiene una trascendencia jurídica muy grande ya que ambos tipos de responsabilidad i) están sujetos

60. A pesar de lo confuso de la terminología, la responsabilidad contractual incluye también al incumplimiento de obligaciones nacidas de fuentes distintas a los delitos y a los cuasidelitos, además de los contratos. Tal sería el caso del incumplimiento de una obligación nacida de un cuasicontrato, por ejemplo. 
a plazos de prescripción distintos ${ }^{61}$; ii) tratan de manera distinta a los daños imprevisibles ${ }^{62}$; iii) dan una distinta importancia a la culpa del actor ${ }^{63}$; iv) tratan de manera distinta al daño moral ${ }^{64} ; \mathrm{y}, \mathrm{v}$ ) deben verificar distintos requisitos para poder someterse a arbitraje; entre otros aspectos.

La causa eficiente del daño tiene mucha relevancia al determinar el quantum del resarcimiento debido por el deudor. En consecuencia, al cuantificar los daños debidos al acreedor habrá que prestar atención a si la fuente del daño es la responsabilidad contractual o la extracontractual.

\subsection{Tipo de daño}

El daño también puede clasificarse dependiendo de qué se haya dañado. Así se distingue entre el daño patrimonial y el daño extrapatrimonial. Se ha dicho que el daño patrimonial es el que se sufre en lo que se tiene, mientras que el daño extrapatrimonial afecta a lo que el sujeto es.

La relevancia de realizar esa distinción es que la cuantificación del daño moral, una categoría de daño extrapatrimonial ${ }^{65}$, está sujeta a reglas muy particulares. Por ejemplo, según ha dicho la jurisprudencia, no se requiere prueba del daño moral una vez que se ha demostrado el hecho dañoso, ya que en tal caso se presume que éste existe y que es una causa de la omisión o de la actuación antijurídica ${ }^{66}$.

61. El daño extracontractual está sujeto a un plazo de prescripción de cuatro años (artículo 2235 del Código Civil), mientras que el plazo de prescripción al tratarse de obligaciones contractuales puede variar, y es generalmente de diez años para las acciones ordinarias y de cinco para las ejecutivas (artículo 2415 del Código Civil).

62. Al tratarse de la responsabilidad contractual, el deudor responde únicamente por los daños previsibles, salvo que haya actuado con dolo (artículo 1574 del Código Civil). Véase, por ejemplo, la sentencia de 18 de diciembre de 2000 de la Primera Sala de lo Civil y Mercantil de la Corte Suprema de Justicia dictada dentro del expediente 501, en el recurso No. 239-2000, publicada en el Registro Oficial 284 de 14 de marzo de 2001.

63. La responsabilidad extracontractual requiere de culpa levísima o, cuando se trata de responsabilidad objetiva, únicamente de la existencia de una relación de causalidad entre hecho ilícito y daño, sin que deba mediar dolo o culpa. La responsabilidad contractual, en cambio, requiere de culpa grave, leve o levísima dependiendo de si el contrato interesa únicamente al acreedor, a ambas partes o únicamente al deudor, respectivamente (artículo 1563 del Código Civil).

64. Nuestro Código Civil no permite el resarcimiento de los daños morales derivados de un incumplimiento contractual.

65. Según ALESSANDRI, el daño extrapatrimonial puede ser moral o biológico. A. ALESSANDRI, M. SOMARRIVA y A. VODANOVIC, Tratado de las obligaciones, 2da. ed. ampliada y actualizada, Editorial Jurídica de Chile: Santiago, 2001, p. 36.

66. Véase, por ejemplo, las siguientes resoluciones de la Primera Sala de lo Civil y Mercantil de la Corte Suprema de Justicia: resolución No. 75-2002, publicada en el Registro Oficial No. 626, de 25 de julio de 2002 y Resolución 
Además, la forma de cuantificar el daño moral es muy particular. El artículo 2232 del Código Civil reza que la determinación del daño moral queda a la prudencia del juez.

Las técnicas de valoración tradicionales no son aplicables para la cuantificación del daño moral. Como explica Zaval de GonZÁles, “[n]unca hay un nexo directo entre la entidad de un perjuicio existencial y la importancia de la condena, porque no puede haberlo entre un mal espiritual y un bien dinerario: los daños morales no son valuables económicamente" 67 . De eso sigue "la radical imposibilidad de aplicar técnicas matemáticas a la hora de decidir la cuantificación indemnizatoria [...]"68.

\subsection{Cláusula penal}

La cláusula penal es una valoración anticipada de los perjuicios sufridos por el acreedor. Como ha dicho la jurisprudencia, "es la avaluación anticipada que las partes hacen en el contrato de los perjuicios que una de ellas pudiere experimentar por el incumplimiento por la otra parte de la obligación convenida, y que deben ser indemnizados por el contratante incumplido"69.

Los métodos de valoración resultan inaplicables cuando el contrato incumplido contempla una cláusula penal, ya que bastará con que el deudor satisfaga el monto allí establecido, independientemente de a cuánto asciendan los daños efectivamente sufridos por el acreedor.

No. 263-2004, publicada en el Registro Oficial No. 43 de 21 de junio de 2005. También véase las siguientes resoluciones de la Segunda Sala: Resolución No. 267-2007, publicada en el Registro Oficial No. 589 de 13 de mayo de 2009 y Resolución No. 357-2007, publicada en el Registro Oficial No. 1 de 11 de agosto de 2009. En este último fallo, la Sala aseveró que "Por lo mismo, en la doctrina y en la jurisprudencia se ha concluido en que el daño moral nono requiere una prueba directa de su existencia”.

67. M. ZAVAla DE GonZÁLEZ, Tratado de daños a las personas. Resarcimiento del daño moral, Buenos Aires: Astrea, 2009, p. 64.

68. Ibídem, p. 65.

69. Fallo de la Primera Sala de lo Civil y Mercantil de la Corte Suprema de Justicia de 24 de mayo de 2001 dictado dentro del expediente de casación 203, dentro del juicio verbal sumario 288-2000, publicado en el Registro Oficial 363 de 6 de julio de 2001. 


\subsection{Congruencia}

Otro aspecto de relevancia es el principio de congruencia de las resoluciones judiciales, recogido en el artículo 273 del Código de Procedimiento Civil. Según esa norma, "[la] sentencia deberá decidir únicamente los puntos sobre que se trabó la litis y los incidentes que, originados durante el juicio, hubieren podido reservarse, sin causar gravamen a las partes, para resolverlos en ella". El principio de congruencia postula que las sentencias no pueden conceder más, menos o algo distinto a lo que el actor ha solicitado, so pena de que la resolución sea incongruente por ultra, infra o extra petita, respectivamente. La incongruencia de los laudos puede ser una causal de nulidad ${ }^{70}$.

El principio de congruencia es importante al cuantificar los daños porque puede ser que el actor pida un resarcimiento menor al que tendría derecho o que pida algo diferente a lo que le correspondería. En cualquiera de esas dos hipótesis, el tribunal no podría otorgar al actor un resarcimiento por todos los daños sufridos, aun si se los hubiera demostrado dentro del proceso.

El actor pediría algo diferente a lo que le correspondería, por ejemplo, si fuera un promitente comprador que reclamara la dación de la cosa prometida en venta. En cambio, un actor pediría menos de lo que tendría derecho a recibir, por ejemplo, si limitara su pretensión a los perjuicios sufridos durante un determinado período, a pesar de haber probado que los daños se prolongaron durante un tiempo mayor.

\subsection{Mora}

El deudor está en mora cuando no ha cumplido con la obligación dentro del plazo convenido expresa o tácitamente ${ }^{71}$, o cuando ha sido judicialmente requerido para el efecto. Una de las consecuencias jurídicas que tiene la mora es que el deudor debe perjuicios desde ese momento.

70. No toda incongruencia permite anular un laudo. Así, la incongruencia por infra petita no está contemplada como una causal de nulidad.

71. Como explica ALESSANDRI, "El plazo tácito se da en aquellas obligaciones que por su naturaleza o por las circunstancias que las rodean necesitan imperiosamente un espacio de tiempo más o menos largo para poder 
En vista de que la mora marca el momento a partir del cual el deudor debe perjuicios, tiene una incidencia importante en la fecha de valoración. Por ejemplo, si una persona accidentalmente destruye un tractor de otra, $y$ ese bien generaba ingresos para su propietario, el cálculo de los perjuicios debe realizarse desde el momento en que el deudor es citado con la demanda y no antes. Sin embargo, el valor del bien (es decir, el daño emergente) debe ser calculado al momento en que se perpetró el ilícito.

\subsection{Exposición al daño}

La apreciación del daño está sujeta a reducción si la víctima se expuso a él imprudentemente ${ }^{72}$. Esta institución, reconocida también en Derecho comparado y aplicada en el arbitraje de inversiones (donde se la conoce como "contributory fault"), tiene por objeto sancionar al acreedor que es parcialmente responsable del daño que ha sufrido. Como explica RiPINsKY, "[w] here the claimant's fault has materially added (ie, contributed) to the loss or damage sustained by the claimant due to the conduct of the respondent, the amount of compensation must be reduced accordingly" 73 .

Esta institución ha sido aplicada en varias ocasiones en el arbitraje de inversiones ${ }^{74}$. Como ha dicho nuestra jurisprudencia, si la imprudencia de la víctima no es la causa exclusiva del daño, ésta "no exonera de responsabilidad al demandado, pero la indemnización deberá ser reducida"75.

\subsection{Mitigación del daño}

El acreedor también está obligado a mitigar los daños que ha sufrido. Esa disposición está consagrada, por ejemplo, en la Convención de las Na-

ser cumplidas". Según el mismo autor, la importancia de este plazo reside en que antes de que transcurra no puede constituirse en mora al deudor. A. Alessandri, M. SOMARriva y A. VODANOviC, Tratado de las obligaciones, 2da. ed. ampliada y actualizada, Santiago: Editorial Jurídica de Chile, 2001, p. 322.

72. Artículo 2230 del Código Civil.

73. S. RIPINSKY, "Assessing Damages in Investment Dispuntes: Practice in search of perfect", Journal of World Investment and Trade, Vol. 10, No. 1, 2009, p. 15.

74. Yukos Universal Limited (Isle of Man) v. Federación Rusa, Caso CPA No. AA 227, p 1637; Occidental Petroleum Corporation y Occidental Exploration and Production Company vs. Ecuador, Caso CIADI No. ARB/06/11, laudo de 5 de octubre de 2012, p. 687.

75. Resolución 246-2012 dictada por la Sala de lo Contencioso Administrativo de la Corte Nacional de Justicia el 24 de agosto de 2012 dentro del recurso de casación No. 139-2010, publicada en la Gaceta Judicial. Año CXIII. Serie XVIII, No. 12. Página 4952. 
ciones Unidas sobre los Contratos de Compraventa Internacional de Mercaderías $^{76}$.

Los tribunales CIADI también han aplicado este principio ${ }^{77}$. El tribunal de Middle East Cement Shipping and Handling, por ejemplo, consideró al deber de mitigar los daños uno de los principios generales del Derecho ${ }^{78}$. Algunos consideran al deber de mitigación de los daños un principio general del comercio internacional ${ }^{79}$.

En el orden local, estimamos que el deber de mitigar los daños es una de las derivaciones del principio de buena fe consagrado en el artículo 1562 del Código Civil.

En consecuencia, el deber de mitigar los daños también tiene una influencia importante en la valoración de los daños, dado que si el perjudicado no tomó las medidas necesarias para mitigar el daño sufrido, la compensación debe ser reducida en esa misma medida.

\section{Resumen y conclusiones}

Como explicamos, son tres los principales métodos de valoración: los intrínsecos, los relativos y los que se basan en el valor de los activos. Cada uno presenta ventajas y desventajas que traen como consecuencia que resulte conveniente aplicarlos en ciertos casos y no en otros.

También vimos que el proceso de valoración tiene varios elementos jurídicos: nuestro ordenamiento contempla una serie de reglas que los jueces y los árbitros deben aplicar al determinar el monto del resarcimiento que el deudor debe ser condenado a pagar.

76. Según el artículo 77 de la Convención, “[1]a parte que invoque el incumplimiento del contrato deberá adoptar las medidas que sean razonables, atendidas las circunstancias, para reducir la pérdida, incluido el lucro cesante, resultante del incumplimiento. Si no adopta tales medidas, la otra parte podrá pedir que se reduzca la indemnización de los daños y perjuicios en la cuantía en que debía haberse reducido la pérdida”.

77. EDF International S.A. $y$ Ors vs. Argentina, Caso CIADI ARB/03/23, laudo de 11 de junio de 2012, p. 1301.

78. Middle East Cement Shipping and Handling Co. S.A. vs. República Árabe de Egipto, Caso CIADI No. ARB/99/6, laudo de 12 de abril 2002, p. 167.

79. B. ZELLER, Damages under the Convention on Contracts for the International Sale of Goods, 2da. Ed., Oxford University Press, pp. 103-104 
A pesar de la importancia que reviste, la valoración de daños dentro del arbitraje quizás no ha recibido la atención que amerita. Si el arbitraje es por antonomasia un método para hacer efectivos derechos de crédito, saber cómo cuantificar esos derechos resulta esencial para que el arbitraje cumpla un fin útil.

Si bien es una labor técnica que debe ser encomendada a expertos en la materia, conviene que los árbitros y los abogados se familiaricen con los conceptos básicos relacionados con la valoración de daños. Los primeros, para fundamentar en mayor medida la decisión que adopten; los segundos, para poder prever con mayor exactitud el resultado de la controversia, y así analizar mejor las conveniencias de dar inicio a un arbitraje.

En suma, el objetivo de este artículo fue hacer un resumen de los aspectos más importantes del proceso de valoración de daños, con aplicación al arbitraje. Si permite despertar el debate en torno a esta cuestión, de modo que la práctica arbitral local dé mayor énfasis a fundamentar técnicamente las decisiones sobre el quantum, entonces nuestro trabajo habrá cumplido su cometido. 